\title{
Displacements of Metallic Thermal Protection System Panels During Reentry
}

\author{
Kamran Daryabeigi, ${ }^{*}$ Max L. Blosser, ${ }^{+}$and Kathryn E. Wurster ${ }^{\ddagger}$ \\ NASA Langley Research Center, Hampton, VA 23681
}

\begin{abstract}
Bowing of metallic thermal protection systems for reentry of a previously proposed single-stage-to-orbit reusable launch vehicle was studied. The outer layer of current metallic thermal protection system concepts typically consists of a honeycomb panel made of a hightemperature nickel alloy. During portions of reentry when the thermal protection system is exposed to rapidly varying heating rates, a significant temperature gradient develops across the honeycomb panel thickness, resulting in bowing of the honeycomb panel. The deformations of the honeycomb panel increase the roughness of the outer mold line of the vehicle, which could possibly result in premature boundary layer transition, resulting in significantly higher downstream heating rates. The aerothermal loads and parameters for three locations on the centerline of the windward side of this vehicle were calculated using an engineering code. The transient temperature distributions through a metallic thermal protection system were obtained using 1-D finite volume thermal analysis, and the resulting displacements of the thermal protection system were calculated. The maximum deflection of the thermal protection system throughout the reentry trajectory was $6.4 \mathrm{~mm}$. The maximum ratio of deflection to boundary layer thickness was 0.032 . Based on previously developed distributed roughness correlations, it was concluded that these defections will not result in tripping the hypersonic boundary layer.
\end{abstract}

\section{Nomenclature}

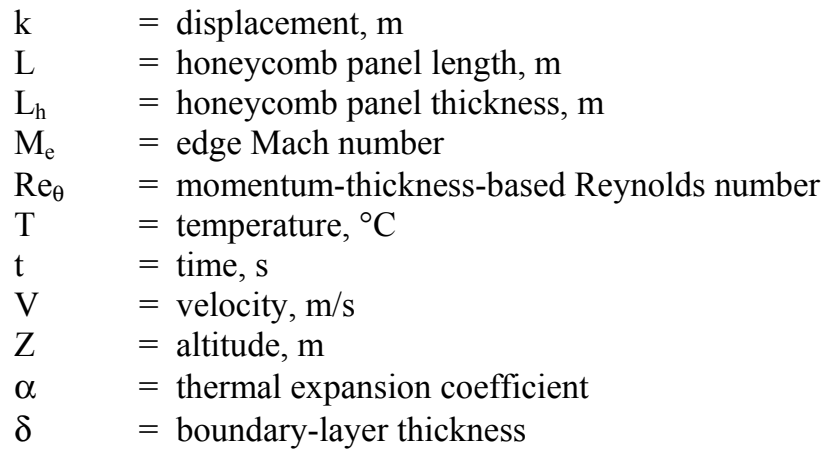

\section{Introduction}

$\mathrm{M}$ ETALLIC thermal protection systems (TPS) were considered for application on X-33, ${ }^{1}$ a proposed space transportation technology demonstrator for the development of a single-stage-to-orbit (SSTO) reusable launch vehicle (RLV). The overall TPS design for X-33 was the largest reusable TPS development effort since the Space Shuttle program. The X-33 was the first RLV to use metallic TPS to cover a major portion of its windward surface. Metallic TPS is a potentially more robust and damage tolerant alternative to the Shuttle ceramic tiles, but its maximum surface temperature is limited to approximately $1000^{\circ} \mathrm{C}$. The outer layer, directly exposed to flow, of current metallic TPS concepts typically consists of a honeycomb panel made of a high-temperature nickel alloy. During portions of reentry flight when the TPS is exposed to rapidly varying heating rates, a significant temperature

\footnotetext{
* Aerospace Technologist, Metals and Thermal Structures Branch, MS 396, Senior Member AIAA

${ }^{+}$Aerospace Technologist, Metals and Thermal Structures Branch, MS 396.

*Aerospace Technologist, Vehicle Analysis Branch, MS 451, Associate Fellow AIAA
} 
gradient develops across the honeycomb panel thickness, resulting in bowing of the honeycomb panel. During rapid heating of the TPS in the early stages of reentry the honeycomb panel's outer facesheet is hotter than the inner facesheet, causing the panel to bow in a convex manner into the boundary layer. However, during rapid cooling of the TPS in the later stages of reentry the outer facesheet is cooler than the inner facesheet, causing the panel to bow in a concave manner. The deformations of the TPS panel increase the roughness of the outer mold line of the vehicle, and may alter the surface heating distribution. This increased surface roughness could cause premature boundary layer transition, resulting in significantly higher downstream heating rates.

The bowing of metallic TPS received significant attention during the X-33 program. Palmer, et al., ${ }^{2}$ used CFD analysis to assess the effects of bowing, steps and gaps of metallic TPS on the surface heating of X-33 for a range of panel deflections from 3 to $15.2 \mathrm{~mm}$, and found maximum heating augmentation factor of 1.26 compared to nominal surface heating. Kontinos and Palmer ${ }^{3}$ performed a numerical simulation of the thermal-structural response of X-33 metallic TPS using the aeroheating predictions of Palmer, et al. ${ }^{2}$ They concluded that even though the bowing caused significant surface temperature variations, the integrated heating load to the TPS did not change. Berry, et al., ${ }^{4}$ experimentally evaluated the effect of distributed roughness caused by bowed metallic TPS panels on the stability of boundary layer in the Langley 20-Inch Mach 6 Air Tunnel. The models tested were based on simple geometrical scaling of predicted 3.8 $-7.6 \mathrm{~mm}(0.15-0.30 \mathrm{in}$.) panel bow heights. They concluded that the bowed panels were qualitatively less effective than discrete trips in causing boundary layer transition, but that the distributed nature of bowed panels could possibly affect a larger percentage of the aft-body than a single trip.

Even though the bowing of metallic TPS for X-33 raised some legitimate concerns about boundary layer transition, but the X-33 flight trajectory was not representative of a typical reentry vehicle. The X-33 trajectory was a hypersonic sub-orbital flight that had a very sharp heating rate peak that caused significant temperature differences across the honeycomb panel thickness. This resulted in a significant bowing of the TPS at flight conditions where the extent of the bowing to boundary-layer thickness was such that it could possibly lead to tripping of the flow. In a typical reentry for a single-stage-to-orbit (SSTO) or two-stage-to-orbit vehicle, the maximum bowing of metallic TPS occurs at very high altitudes, where boundary-layer thickness is orders of magnitude larger than the resulting deflections of the TPS.

The objective of this study is to investigate the bowing of metallic TPS for typical reentry trajectories of SSTO vehicles, and determine whether the resulting bowing could cause boundary layer transition.

\section{Vehicle and TPS}

The vehicle chosen for this study was a lifting body configuration SSTO launch vehicle in the VentureStar ${ }^{\mathrm{TM}}$ size and payload class designated as RLV-0003c $\mathrm{c}^{5}$ shown in Fig. 1. The overall length of the vehicle, distance from nose cap to hinge line, is $34.6 \mathrm{~m}$. A plot of the corresponding reentry flight profile is provided in Fig. 2 where the vehicle reentry altitude, velocity, and Mach number histories are shown. ${ }^{6}$ This is a $2570 \mathrm{~s}$ long reentry, with reentry velocity of $7.63 \mathrm{~km} / \mathrm{s}$ at an altitude of $122 \mathrm{~km}$. The flow is hypersonic until $1970 \mathrm{~s}$ into reentry. The aerothermal loads and parameters for three locations on the centerline of the windward

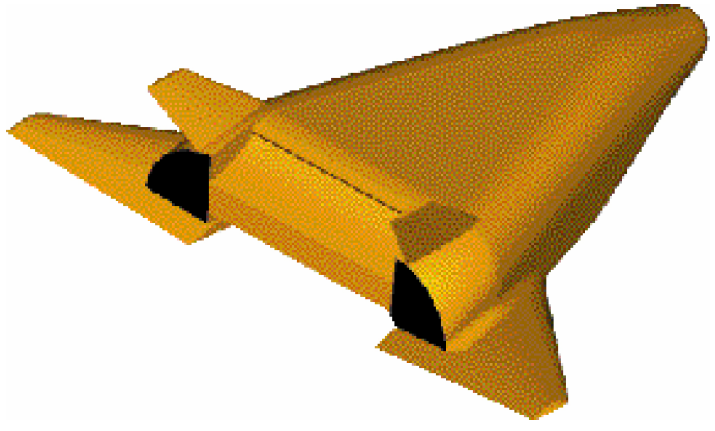

Figure 1. Lifting body RLV-0003c. side of this vehicle at axial stations of 6.1,20.4, and $30.4 \mathrm{~m}$. (240, 802, and 1199 in.) downstream of the nose cap were calculated using the MINIVER $^{7}$ engineering code. Relevant aerothermal parameters such enthalpy-based convective heat transfer coefficient, recovery enthalpy, momentum thickness, and momentum-thickness-based Reynolds number were calculated from the engineering code output. 
The metallic TPS used for this study is the Adaptable, Robust, Metallic, Operable Reusable (ARMOR) thermal protection system developed by Langley Research Center. ${ }^{8}$ The overall TPS panel has dimensions of 457 x 457 x $89 \mathrm{~mm}(18 \times$ $18 \times 3.5$ in.). The major components of ARMOR are: an Inconel 617 honeycomb panel which forms the outer surface of the TPS, a thin-guage titanium box beam frame that defines the edges of the panel's interior surface, four stand-off support brackets that connect the outer honeycomb panel to the inner titanium box beam frame, four compliant bellows-type tubes for bolt access, bulged compliant sides, titanium foil closeout and Saffil ${ }^{\mathrm{TM}}$, a loose alumina fibrous insulation. Photographs of the ARMOR panel are shown in Fig. 3. Fig. 3a shows the complete assembly, while Fig 3.b shows the metallic skeleton of the panel, including the Inconel 617 honeycomb panel. The ARMOR panel and its components are described in detail elsewhere, ${ }^{8}$ but because the bowing occurs due to temperature gradients across the outer honeycomb panel thickness, a brief description of this panel will be provided here. The honeycomb panel consisted of $0.15-\mathrm{mm}$ (0.006 in.) thick Inconel 617 facesheets brazed to 6.3-mm (0.25 in.) thick Inconel 617 honeycomb core with $4.7-\mathrm{mm}(3 / 16 \mathrm{in}$.) corrugated square cells with $0.038-\mathrm{mm}(0.0015$-in.) thick cell walls. A coating that simultaneously increases the surface emissivity and provides oxidation protection was applied to the outer facesheet. This coating consisted of an alumina base layer and a two-phase glass outer layer with a total thickness of approximately $0.005 \mathrm{~mm}\left(0.2 \times 10^{-3}\right.$ in) with an emissivity of $0.86 .^{9}$

\section{Analysis}

A 1-D finite volume thermal numerical model for ARMOR TPS was used to provide thermal response of the TPS to the aerothermal loads. The overall thermal modeling formulation used was similar to the one provided by Poteet, et al. ${ }^{10}$ The thermal boundary conditions consisted of enthalpy-based convective heating at the aerodynamic surface and adiabatic conditions at the backface. The imposed convective heating at the surface was balanced by re-radiation to space, and effective heat conduction and storage through the honeycomb panel. The effective thermal conductivity of the honeycomb panel was calculated based on the Swann and Pittman model. ${ }^{11}$

For a flat honeycomb panel, the displacement of the honeycomb panel can be modeled analytically using geometrical considerations. Consider the two facesheets of the honeycomb panel with temperature and thermal expansion coefficients of $T_{1}, \alpha_{1}$, and $T_{2}, \alpha_{2}$, respectively, as shown in Fig. 4. The displacement of the outer facesheet can be calculated from:

$$
k_{1}=L_{h}\left(\frac{\alpha_{1} T_{1}+1}{\alpha_{1} T_{1}-\alpha_{2} T_{2}}\right)\left\{1-\cos \left[\frac{L}{2 L_{h}}\left(\alpha_{1} T_{1}-\alpha_{2} T_{2}\right)\right]\right\}
$$


Where $\mathrm{L}_{\mathrm{h}}$ and $\mathrm{L}$ are the honeycomb panel thickness and length. If $\alpha_{1}=\alpha_{2}=\alpha$, and $\alpha_{1} \mathrm{~T}_{1}<<1$, then Eq. (1) reduces to:

$$
k_{1}=\frac{L_{h}}{\alpha\left(T_{1}-T_{2}\right)}\left\{1-\cos \left[\frac{L \alpha\left(T_{1}-T_{2}\right)}{2 L_{h}}\right]\right\}
$$

So if the honeycomb panel thickness and thermal expansion coefficients of the facesheets are known, the displacement of the honeycomb panel can be calculated from the temperature difference between the facesheets. If the temperature gradient across the honeycomb panel thickness is positive, zero, or negative, the honeycomb panel will bow out (convex), stay flat, or bow in (concave), respectively. As can be seen the main driver for the bowing of the honeycomb panel is the temperature gradient across the panel thickness, and this temperature gradient is largest when the panel is experiencing rapid heating or cooling.

Once the temperature distributions through the ARMOR panel are obtained through the solution of the 1-D finite volume formulation of the conservation of energy equation, then the temperature gradients through the honeycomb panel are used in conjunction with Eq. (2) to obtain the displacements of the honeycomb panel.

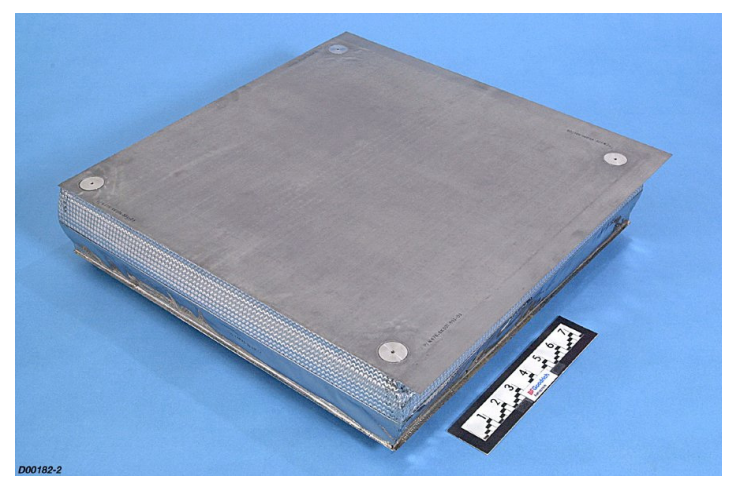

\section{Results and Discussion}

The resulting surface temperatures of ARMOR TPS at the three axial stations of 6.1, 20.4 and $30.4 \mathrm{~m}$ from the nose of the vehicle on the windward surface centerline are shown in Fig. 5. There is a rapid surface temperature rise between 0 and $450 \mathrm{~s}$, after which the surface temperatures achieve quasi steady-state values of 800,660 , and $610^{\circ} \mathrm{C}$ at the $6.1,20.4$, and $30.4 \mathrm{~m}$ stations, respectively. This is followed by rapid surface cooling between 1500 and $2400 \mathrm{~s}$. Boundary layer transition occurs at approximately $1840 \mathrm{~s}$ into the reentry flight as noticed by the sudden change of slope in the surface temperature histories. This boundary layer transition occurs during the surface cooling part of the flight, and the resulting increased heating does not adversely affect TPS performance. The trajectory for this vehicle had been carefully tailored to delay the onset of transition. ${ }^{6}$ The main concern is for premature boundary layer transition during the extreme heating portions of the flight (up to 1500 s), where boundary layer transition could results in significant augmentation of the already high heating rates, resulting in TPS exceeding its temperature limits, and having a significantly higher integrated heat load. The resulting temperature differences across the honeycomb panel thickness at the three axial stations of 6.1, 20.4 and $30.4 \mathrm{~m}$ are shown in Fig. 6 . The maximum temperature differences are $65^{\circ} \mathrm{C}, 52^{\circ} \mathrm{C}$, and $49^{\circ} \mathrm{C}$ for the $6.1,20.4$, and $30.4 \mathrm{~m}$ axial stations, respectively. The temperature differences have a nominal value of $10^{\circ} \mathrm{C}$ between 500 and $1500 \mathrm{~s}$, after which they become negative, implying that the outer honeycomb panel facesheet is cooler than the inner honeycomb panel 
facesheet. The temperature difference across the honeycomb panel thickness reaches $-20^{\circ} \mathrm{C}$ between 1900 and $2200 \mathrm{~s}$ for the 20.4 and 30.4 stations, while a minimum temperature difference of $-32^{\circ} \mathrm{C}$ is achieved at the $6.1 \mathrm{~m}$ station.

The corresponding deflections of the ARMOR TPS, with honeycomb panel thickness and length of 6.3 and $457 \mathrm{~mm}$, at the three axial stations throughout the trajectory are shown in Fig. 7. The length used in Eq. (2) was based on the diagonal of the $457-\mathrm{mm}$ square honeycomb panel. The deflections follow the general pattern of the temperature differences shown in Fig. 6. The maximum deflections are $6.1 \mathrm{~mm}, 5.2 \mathrm{~mm}$, and 5.0 $\mathrm{mm}$ at the 6.1, 20.4, and $30.4 \mathrm{~m}$ stations, respectively. The X-33 deflections were estimated to be in the range of $3.8-7.6 \mathrm{~mm} .{ }^{4}$ The deflections go from $2 \mathrm{~mm}$ at $500 \mathrm{~s}$ to $0 \mathrm{~mm}$ at $1500 \mathrm{~s}$, after which they go negative and achieve minimum values of $-3.6,-2.4$, and $-2.2 \mathrm{~mm}$ at the three

stations. Therefore, for the first $1500 \mathrm{~s}$ of reentry flight, the metallic TPS bows out into the boundary layer in a convex manner. This convex bowing may cause flow disturbances that may lead to hypersonic boundary-layer transition induced by the surface roughness. After $1500 \mathrm{~s}$, the panel bows in a concave manner. The flow also transitions from hypersonic to supersonic around $1900 \mathrm{~s}$, therefore the concave bowing of the metallic TPS after $1500 \mathrm{~s}$ may not cause significant overheating issues related to boundary layer transition. In order to assess the significance of the convex bowing, its relative magnitude with respect to the boundary-layer thickness needs to be investigated. The boundary-layer thickness was assumed to be equal to 5.5 times the calculated momentum thickness ${ }^{12}$ from the engineering code results. This factor is generally valid for laminar boundary layer and cold wall assumptions, and may be higher for hot-wall conditions. Anyhow, use of the lower factor of 5.5 leads to a more conservative analysis. The ratio of the ARMOR panel deflection to boundary layer thickness $(\mathrm{k} / \delta)$ for the three axial stations are plotted in Fig. 8. Based on the preceding discussion, data are only shown for reentry times of less than $1500 \mathrm{~s}$, time durations where the TPS bows out into the boundary layer. At each station there are two distinct peaks in the $\mathrm{k} / \delta$ values. At the $6.1 \mathrm{~m}$ station the maximum value of $\mathrm{k} / \delta$ is 0.032 . The maximum values of $\mathrm{k} / \delta$ are 0.016 and 0.013 for the 20.4 and $30.4 \mathrm{~m}$ stations, respectively. The deflections of the metallic TPS are less than four percent of the boundary-layer thickness during the hypersonic portion of the reentry flight. To gain further insight, the ratio of deflection to boundary-layer thickness for the $6.1 \mathrm{~m}$ station which had the highest deflections is shown in Fig 9, along with the corresponding ratio of momentum-thickness-based Reynolds number to edge Mach number $\left(\mathrm{Re}_{\theta} / \mathrm{M}_{\mathrm{e}}\right)$. At reentry times of 346 and $1360 \mathrm{~s}$ corresponding to maximum $\mathrm{k} / \delta$ of 0.032 , the corresponding values of $\mathrm{Re}_{\theta} / \mathrm{M}_{\mathrm{e}}$ are 28 and 92 . The $\mathrm{k} / \delta$ of 0.032 is below the threshold of discrete roughness values $(0.2)$ and falls under the distributed roughness range. ${ }^{13}$ Based on distributed roughness studies for the Space Shuttle Orbiter, $R_{\theta} / \mathrm{M}_{\mathrm{e}}$ should be above the range of 250-300

American Institute of Aeronautics and Astronautics 
in order to cause boundary layer transition. ${ }^{13}$ Therefore, it can be concluded that a distributed roughness with $\mathrm{k} / \delta$ of 0.032 at $\mathrm{Re}_{\theta} / \mathrm{M}_{\mathrm{e}}$ of 92 , does not result in tripping the hypersonic boundary layer.

The reported results relate to the specific ARMOR TPS honeycomb panel geometry, 6.3$\mathrm{mm}$ thick and 457-mm square panel. The sensitivity of the metallic TPS to honeycomb panel size and thickness was further investigated. Panel thicknesses of 6.3 and $12.6 \mathrm{~mm}$, and panel lengths of 457, 685.5, and $914 \mathrm{~mm}$ were considered. The resulting temperature difference across the honeycomb panel thickness, deflection, and ratio of deflection to boundary-layer thickness followed the same trends as shown in Figs. 6-8 for the 6.3$\mathrm{mm}$ thick $457-\mathrm{mm}$ square panel, but had different amplitudes. The maximum values of temperature difference across the honeycomb panel thickness $(\Delta \mathrm{T})$, deflection $(\mathrm{k})$, and ratio of deflection to boundary-layer thickness $(\mathrm{k} / \delta)$ are presented in Table 1. Increasing the honeycomb panel thickness increases the maximum temperature difference across the honeycomb panel, but does not significantly effect the deflection and $\mathrm{k} / \delta$. Increasing the panel length increases the maximum deflections. For the $6.3-\mathrm{mm}$ thick honeycomb panel the maximum deflection increases from 6.4 to $25.4 \mathrm{~mm}$ for panel lengths of 457 and $914 \mathrm{~mm}$. Increasing the panel length from 457 to $914 \mathrm{~mm}$ also results in increased values of $\mathrm{k} / \delta$, from 0.032 to 0.127 for the $6.3-\mathrm{mm}$ thick honeycomb panel. These $\mathrm{k} / \delta$ values and their corresponding $\mathrm{Re}_{\theta} / \mathrm{M}_{\mathrm{e}}$ values (28 and 92) are below the threshold $\mathrm{Re}_{\theta} / \mathrm{M}_{\mathrm{e}}$ of 250-300 required for distributed roughness boundary layer transition. ${ }^{13}$ The experimentally derived correlations representing Mach 6 transition onset (incipient) and fully turbulent flow (effective) for X-33 by Berry, et al., ${ }^{4}$ are shown in Fig. 10, where $\mathrm{Re}_{\theta} / \mathrm{M}_{\mathrm{e}}$ is plotted versus $\mathrm{k} / \delta$. The data from Table 1 are also shown in this figure. The ratio of deflection to boundary layer thickness for the various metallic TPS configurations fall well below the critical values required to cause transition onset based on either discrete or distributed roughness.

\section{Concluding Remarks}

Bowing of metallic TPS for reentry of a singlestage-to-orbit lifting body reusable launch vehicle was studied. During portions of reentry when the TPS is exposed to rapidly varying heating rates, a

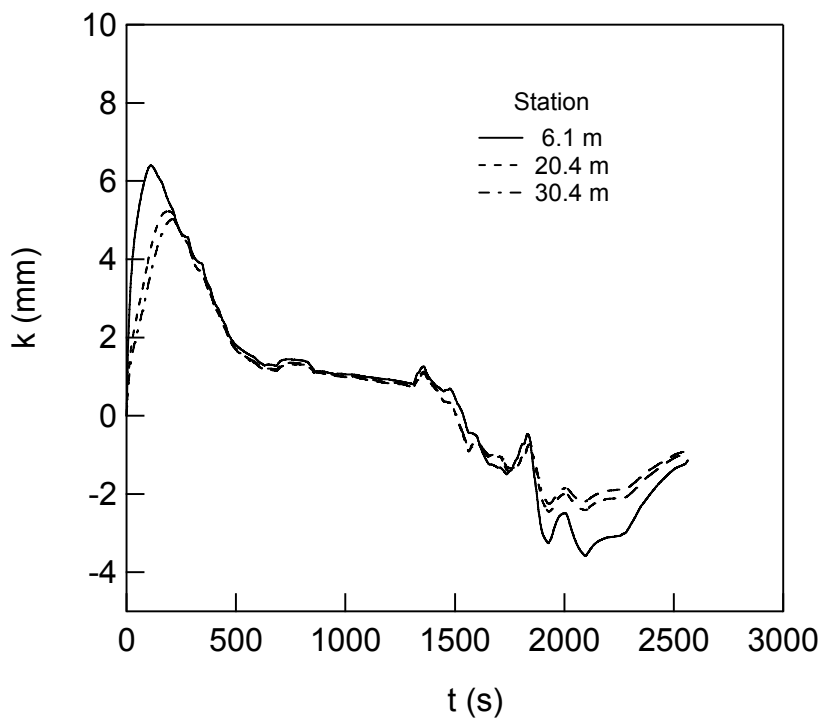

Figure 7. Deflection of ARMOR TPS at three stations on windward surface centerline.

\begin{tabular}{|c|c|c|c|c|}
\hline $\mathrm{L}(\mathrm{mm})$ & $\mathrm{L}_{\mathrm{h}}(\mathrm{mm})$ & $\begin{array}{c}\operatorname{Max} \Delta \mathrm{T} \\
\left({ }^{\circ} \mathrm{C}\right)\end{array}$ & $\begin{array}{c}\text { Max k } \\
(\mathrm{mm})\end{array}$ & $\operatorname{Max} \mathrm{k} / \delta$ \\
\hline 457 & 6.3 & 65.3 & 6.4 & 0.032 \\
\hline 685.5 & 6.3 & 65.3 & 11.3 & 0.056 \\
\hline 914 & 6.3 & 65.3 & 25.4 & 0.127 \\
\hline 457 & 12.6 & 122.6 & 6.0 & 0.028 \\
\hline 685.5 & 12.6 & 122.6 & 10.7 & 0.051 \\
\hline 914 & 12.6 & 122.6 & 24.2 & 0.114 \\
\hline
\end{tabular}

Table 1. Variation of maximum temperature difference across honeycomb panel thickness, deflection, and ratio of deflection to boundary-layer thickness with honeycomb

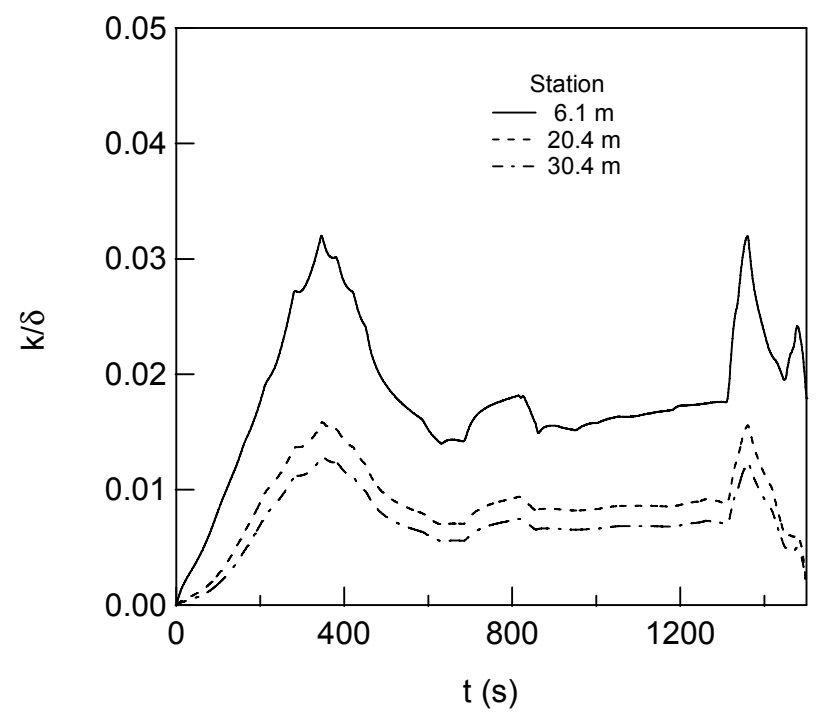

Figure 8. Ratio of TPS deflection to boundary-layer thickness at three stations on windward surface centerline.

6

American Institute of Aeronautics and Astronautics 
significant temperature gradient develops across the honeycomb thickness, resulting in bowing of the honeycomb panel. The deformations of the TPS panel increase the roughness of the outer mold line of the vehicle, which could possibly result in premature transition to turbulent flow, resulting in much higher downstream heating rates. The aerothermal loads and parameters for three locations on the centerline of the windward side of a lifting body reusable launch vehicle designated as RLV-0003c were calculated using an engineering code. The transient temperature distributions through the ARMOR TPS were obtained using 1-D finite volume thermal analysis, and the resulting displacements of the TPS were calculated. The maximum deflection of the TPS throughout the reentry trajectory was $6.4 \mathrm{~mm}$, while the maximum ratio of deflection to boundary-layer thickness was 0.032 , occurring at approximately 346 and $1350 \mathrm{~s}$ during the reentry. The corresponding ratios of the momentumthickness-based Reynolds number to edge Mach number at these instances (346 and $1350 \mathrm{~s}$ ) were 28 and 92 . Based on previously developed discrete and distributed roughness correlations it was concluded that these defections will not result in tripping the hypersonic boundary layer.

\section{References}

1. Cook, S. A., "The X-33 Advanced

Technology Demonstrator," AIAA Paper 96-1195, April 1966.

2. Palmer, G., Kontinos, D. A., and Sherman, B., "Surface Heating Effects of X-33 Vehicle TPS Panel Bowing, Steps, and Gaps," AIAA Paper 980865, January 1998.

3. Kontinos, D. A., and Palmer, G., "Numerical Simulation of Metallic TPS Panel Bowing" AIAA Paper 98-0866, January 1998.

4. Berry, S. A., Horvath, T. J., Hollis, B. R., Thompson, R. A., Hamilton, H. H., II, "X-33

Hypersonic Boundary-Layer Transition," Journal of Spacecraft and Rockets, Vol. 38, No. 5, pp 646-657, 2001.

5. Lockwood, M. K., "Overview of Conceptual Design of Early VentureStar ${ }^{\mathrm{TM}}$ Configurations," AIAA Paper 2000-1042, January 2000.

6. Tartabini, P. V., Wurster, K. E., Korte, J. J., and Lepsch, R. A., "Multidisciplinary Analysis of a Lifting Body Launch Vehicle," Journal of Spacecraft and Rockets, Vol. 39, No. 5, pp 788-795, 2002.

7. Engel, C. D., and Praharaj, S. C., "MINIVER Upgrade for the AVID System, Vol. I: LANMIN User's Manual," NASA CR-172212, August 1983.

8. Blosser, M. L., Chen, R. R., Schmidt, I. H., Dorsey, J. T., Poteet, C. C., Bird, R. K., and Wurster, K. E., "Development of Advanced Metallic Thermal-Protection-System Prototype Hardware," Journal of Spacecraft and Rockets, Vol. 41, No. 2, pp 183-194, 2004.

9. Bird, R. K., Wallace, T. A., and Sankaran, S. N., "Development of Protective Coatings for High-Temperature Metallic Materials," Journal of Spacecraft and Rockets, Vol. 41, No. 2, pp 213-220, 2004.

American Institute of Aeronautics and Astronautics 
10. Poteet, C. C., Abu-Khajeel, H., Hsu, S.-Y., "Preliminary Thermal-Mechanical Sizing of Metallic Thermal Protection System," Journal of Spacecraft and Rockets, Vol. 41, No. 2, pp 173-182, 2004

11. Swann, R.T., and Pittman, C.M., "Analysis of Effective Thermal Conductivities of Honeycomb-Core and Corrugated-Core Sandwich Panels," NASA Technical Note D-714, April 1961.

12. Schlichting, H., Boundary Layer Theory, $7^{\text {th }}$ Ed., McGraw-Hill, New York, 1979.

13. Berry, S. A., Bouslog, S. A., Brauckmann, G. J., and Caram, J. M., "Boundary Layer Transition Due to Isolated Roughness - Shuttle Results From the LaRC 20-inch Mach 6 Tunnel,” AIAA 1997-0273, January 1997. 